INFO- 142

Primljeno/Received:2019-02-03

10.32914/mcpr.10.1.7
UDK: 004.8

Professional Paper/Stručni rad

\title{
UMJETNA INTELIGENCIJA
}

\author{
Vladimir Prister \\ Hrvatsko Komunikološko društvo \& Hrvatska radio -televizija, Zagreb, Hrvatska
}

\begin{abstract}
Sažetak koji se bori za primat na ovom vrlo zanimljivom polju.

Ključne riječi

Umjetna inteligencija, industrijska revolucija, budućnost
\end{abstract}

Prikazan je kratki povijesni uvod u sve četiri industrijske revolucije. Autor prikazuje sedam segmenata 4. industrijske revolucije zbog njihove važnosti. Rad opisuje neke vrlo važne aspekte umjetne inteligencije (UI) i njihov utjecaj. Navedeni primjeri složenog odnosa stroj - čovjek (IBM Deep Blue - Garry Kasparov i IBM Watson). Naglašena je važnost konferencije Dartmouth, Hanover, New Hampshire, 1956. Velike mogućnosti prikazane su i primjerom humanoidnog robota Atlas (Boston Dynamics - DARPA). Na kraju, daje se primjer Japana

Nekoliko kratkih, uvodnih rečenica:

Prvu industrijsku revoluciju datiramo na prijelaz iz 18. na 19. stoljeća, a započela je u Europi i Sj.Americi. U to vrijeme društvo se iz poljodjelskog i uglavnom seoskog pretvara u građansko i industrijsko. James Watt i njegov parni stroj odigrali su glavnu ulogu u prvoj industrijskoj revoluciji. Druga je započela 1870. traje, okvirno, do 1914. Obilježava ju nagli razvitak industrije, osobito čelika i nafte. Tu je veliku, presudnu ulogu ostvario Nikola Tesla sa svojim epohalnim otkrićima, zatim pojava telefona, električne rasvjete, gramofona i vozila s untarnjim sagorijevanjem. Treća industrijska revolucija koju neki nazivaju još i digitalnom, započela je u 1980-tim godinama prošlog stoljeća. Obilježili su je osobna računala, internet $\mathrm{i}$ eksplozivni razvitak informacijske $\mathrm{i}$ komunikacijske tehnologije (tzv. ICT).

Mi upravo svjedočimo naglom prodiranju najnovijih izuma koje je iznjedrila najnovija, četvrta industrijska revolucija koja ulazi u sve pore našeg života. I mijenja ga!

Umjetna inteligencija (UI) ili izvorno engleski Artificial Inteligency (akronim AI), jedna je od sedam dragocjenih novih, moćnih sastavnica 4. industrijske revolucije. To su redom:

\section{Umjetna inteligencija}

2. Robotika

3. Nanotehnologija

4. Internet stvari (Internet of Things, IoT)

5. Autonomna vozila

6. Kvantna računala

7. 3D tisak (Ispis u tri dimenzije)

Dozvolite mi na početku poneku usputnu digresiju:

Političke i socijalne reperkusije korištenja robota su ogromne: zamjenjujući radnika $u$ nespremnim i neprilagođenim društvima izazivaju proteste, opću nelagodu i nesigurnost otpuštanja radnika. Istodobno, primjerice, $\mathrm{u}$ Mercedesu, na automatskoj liniji za proizvodnju automobila, jedan jedini industrijski robot zamjenjuje mnogo radnika uz istodobno povećanje brzine, točnosti izrade i smanjenja utroška energije. Za samu tvornicu korist je neusporediva! A u ovom konkretnom primjeru ove svjetski poznate tvrtke Mercedes - radnici su prebačeni na poslove ručnog završnog poliranja dijelova karoserije, postavljanja logotipa tvrtke i druge 
jednostavne poslove koji ne traže veliku stručnost! (SIC!).

Evo još jedne digresije:

Nanotehnologija (grčki "nanos" = patuljast), bavi se tehnologijom, sklopovima, elementima

i jedinicama reda veličine milijarditog dijela metra! Američki su znanstvenici sa Sveučilišta u Stanfordu uz pomoć nanotehnologije razvili novu metodu borbe protiv raka kojom se ne oštećuje zdravo tkivo! Metoda se sastoji od umetanja nano cijevčica $u$ stanice raka $\mathrm{i}$ njihovog zagrijavanja pomoću lasera. Spomenute nanocijevčice imaju promjer polovine promjera molekule DNK pa ih $\mathrm{u}$ prosječnu stanicu stane nekoliko tisuća. Nakon što se nanocijevčice koje su izrađene od ugljika izlože laserskom infracrvenom dijelu spektra u trajanju od 2 minute, dolazi do njihova zagrijavanja na $70^{\circ} \mathrm{C}$ i umiranja stanica $u$ kojima se nalaze! A ako se antitijela pričvrste za nanocijevčice moguće je precizno naciljati određeni tip stanica raka koje je potrebno eliminirati. Ogromna je to prednost pred standardnom kemoterapijom jer se kod nje usmrćuje i propada osim tumorskih i velik broj zdravih stanica.

No, krenimo dalje: Internet stvari (Internet of Things, IoT) je nova tehnologija koja umrežava i povezuje uređaje. Tim korakom umreženi uređaji i senzori ulaze $u$ naš život postajući dio Interneta stvari. To je potpuno novi aspekt u razvoju Interneta. Koristivši IP protokol stvara se infrastruktura za razvoj potpuno novih mobilnih i web usluga $\mathrm{s}$ neopisivo korisnim mogućnostima. Primjerice: dobivanje pametne kuće koja štedi energiju, pametnog ureda i okoliša, vaš ured dobiva bezbroj novih izvanredno korisnih aplikacija.

I autonomna vozila su već tu:

Vozilo bez vozača, nekad davno samo luda ideja, danas je stvarnost! Jasno, vojna je indusrija bila glavni ulagač u skupa istraživanja i realizaciju autonomnih vozila.

Međutim, danas svaka ozbiljna automobilska tvrtka već posjeduje ili razvija nove modele i ima $u$ svom programu izradu i razvoj autonomnog modela, tj. automobila bez vozača! Svaka! Čak je i Google ponudio svoju inačicu malog automobila kojemu vozač više nije potreban. Malen jest po dimenzijama ali velik po mogućnostima.

Kvantna računala:

Kad se $u$ stručnim krugovima povede razgovor o kvantnim računalima, pozornost osobito poraste! Naime, znameniti IBM i NASA ulažu ogromna sredstva u razvoj na polju kvantnih računala. A zašto je tome tako? Izgleda da su stvarni resursi na ovom polju ogromni. Iako prve ideje o kvantnom računalu bivaju smještene u daleku 1980. godinu, kad je matematičar J.I.Manin postavio prve ideje, znanstvenik Richard Feyneman se godinu kasnije založio za izradu novih računala koja bi se zasnivala na zakonima kvantne mehanike! Sadašnja računala koriste bitove (0 i 1). Ili 0 ili 1! Međutim, kvantni bit odnosno qubit, može biti ili 1 ili 0 ali i 1 i 0 istovremeno (tzv. kvantna superpozicija)! Baš ovo spomenuto svojstvo kvantnim računalima omogućuje da funkcije obavljaju puno, puno brže. Kao primjer i dokaz ovom navodu može poslužiti primjer izvedbe kvantnog računala tvrtke D-Wave koje je na testiranju bilo 3600 puta brže! No, sad stiže frapantni podatak datiran u drugi dio 2015. godine, da su NASA i Google na kvantnom računalu D-Wave $2 X \mathrm{~s}$ više od 1000 qubita, postigli brzine 100 milijuna puta veće od onih kod običnog računala. A ogromna korist od super brzih kvantnih računala tek se može naslutiti! Njima bi bilo moguće pratiti ponašanje čestica $u$ posebnim uvjetima. To danas radimo samo $u$ velikim i skupim akceleratorima. Bila bi omogućena puno jeftinija izrada i testiranje novih lijekova, prognozirati ili čak spriječiti neke bolesti.

3D tisak (3D printing):

Tisak, ispis u tri dimenzije nova je metoda brze izrade neophodnih prototipova raznih objekata i uređaja. Izvorno, radi se o patentu znamenitog MIT-a (Massachusetts Institute of Technology) kojim se izravno iz 3D CAD programa izrađuju predmeti $u$ prostoru! Trodimenzionalni ispis osobito je dragocjen na mnogim područjima: dizajn, informatika, arhitektura, elektronika/elektrotehnika, 
strojarstvo, brodogradnja, medicina, molekularna kemija, bio-modeliranje, umjetnost i očuvanje spomenika kulture i još mnogo drugih! A sada bih se želio vratiti umjetnoj inteligenciji! Alan Mathison Turing, britanski matematičar, kriptograf i računalni teoretičar, objavio je 1950. godine provokativan članak koji je i do danas ostao predmetom žučnih stručnih rasprava i polemika. Naime, on u članku "Računalni strojevi i inteligencija" izravno navodi:

\# Predlažem da razmotrimo pitanje: "Mogu li strojevi misliti?".

Ovo bi trebalo započeti definicijama značenja pojmova "stroj" i "misliti". Definicije mogu biti uokvirene tako da u najvećoj mogućoj mjeri reflektiraju normalnu uporabu riječi, ali ovaj je stav opasan, ako se smisao riječi "stroj" i "misli" mogu naći ispitivanjem kako se obično koriste i teško je izbjeći zaključak da značenje i odgovor na pitanje "Mogu li strojevi misliti" treba tražiti u statisičko istraživanju kao što je Gallupova anketa. Ali ovo je apsurdno. Umjesto pokušaja takve definicije zamjenit ću pitanje drugom što je usko povezano s njom i izraženo je u relativno jednoznačnim riječima.

\# Hrvatska enciklopedija, mrežno izdanje, Leksikografski zavod Miroslav Krleža, za natuknicu "umjetna inteligencija" navodi:

UMJETNA INTELIGENCIJA

umjetna inteligencija (UI, prema engl. akronimu AI, od Artificial Intelligence), dio računalne znanosti (informatike) koji se bavi razvojem sposobnosti računala da obavljaju zadaće za koje je potreban neki oblik inteligencije, tj. da se mogu snalaziti $u$ novim prilikama, učiti nove koncepte, donositi zaključke, razumjeti prirodni jezik, raspoznavati prizore i dr. Naziv se također rabi za označivanje svojstva svakog neživog sustava koji pokazuje inteligenciju (inteligentni sustav); obično su to računalni sustavi, dok se izraz katkad neutemeljeno primjenjuje na robote, koji nisu nužno inteligentni. Inteligentnim sustavom smatra se svaki sustav koji pokazuje prilagodljivo ponašanje, uči na temelju iskustva, koristi velike količine znanja, pokazuje svojstva svjesnosti, komunicira $\mathrm{s}$ čovjekom prirodnim jezikom i govorom, dopušta pogreške i nejasnoće $u$ komunikaciji ili dr. xxx Funkcije inteligentnog sustava jesu: prikupljanje i obrada informacija, interakcija $\mathrm{s}$ radnom okolinom, komunikacija s čovjekom ili s drugim inteligentnim sustavima, prikupljanje i obrada znanja, zaključivanje, te planiranje. Dok se pod ljudskom inteligencijom smaraju čovjekove mogućnosti da istodobno pokazuje različite inteligente odlike $i$ obavlja takve funkcije, današnji su inteligentni sustavi ponajprije specijalizirani za pojedinu mogućnost.

Iako mlada znanost, umjetna inteligencija naslijedila je mnoge zamisli, pristupe i tehnike iz drugih disciplina, a napose onih koje se bave istraživanjem načina ljudskog mišljenja: kognitivne znanosti, logike, psihologije, biologije, filozofije, lingvistike, matematike i dr.

Neka od glavnih područja i primjena umjetne inteligencije jesu: računalne igre i simulacije (najizrazitiji su primjer šahovski sustavi, kakav je npr. bio Deep Blue koji je 1997. pobijedio svj. Prvaka G. Kasparova), ekspertni sustavi, neuronske mreže, razumijevanje i obradba prirodnih jezika (razumijevanje govora, prevođenje), računalni vid (prepoznavanje uzoraka ili predmeta, analiza scene), rješavanje problema, pretraživanje podataka, automatsko programiranje, inteligentni agenti i dr. Prema stupnju inteligencije, umjetnu inteligenciju dijeli se na tzv. jaku i slabu. Jaka umjetna inteligencija $u$ tolikoj je mjeri razvijena da može razmišljati na istoj razini kao i čovjek; za prepoznavanje takva oblika inteligencije, već je A.M.Turing razvio test prema kojemu je računalo inteligentno ako više od $30 \%$ osoba koje s njim neizravno komuniciraju nije sposobno odrediti je li riječ o čovjeku ili stroju. Slaba umjetna inteligencija jest ona kojoj se mogu pripisati tek neka inteligentna svojstva, npr. mogućnost prepoznavanja govora.

Iako su se ideje o umjetnoj inteligenciji pojavljivale $\mathrm{u}$ literaturi pa i mitovima (npr. mit o Golemu) već od pradavnih vremena, njezin je razvoj započeo pojavvom digitalnih računala u drugoj pol. XX. stoljeća. Među prve teoretske radove iz toga područja ubrajaju se radovi A.M.Turinga, dok se prvim računalnim programom umjetne inteligencije smatra The Logic Theorist (engl. Logički teoretičar; 1955.). Izraz umjetna inteligencja skovan je na 
kongresu na Darthmouth Collegeu 1956., koji je, okupivši pionire toga područja, potaknuo sustavnaistraživanja. Taj je kongres organizirao John McCarthy, koji je potom postao autor osnovnoga programskog jezika umjetne inteligencije LISP-a (1958.), te ga se danas smatra začetnikom umjetne inteligencije. Nakon početnih optimističkih prognoza u 1960-ima je sva složenost postizanja umjetne inteligencije koja bi bila mjerljiva s ljudskom izašla na vidjelo, te su se istraživanja usmjerila prema parcijalnim rješenjima pojedinih problema. Tako je 1961. razvijen šahovski program koji je igrao na razini majstora, 1965. stroj koji se koristio rezolucijom kao metodom logičkog zaključivanja, a iste godine započeo je rad na glasovitom eksperimentalnom programu Dendral. Poč. 1970-ih razvijen je programski jezik PROLOG, te potom prvi zaista uporebljivi ekspertni inteligentni sustavi, kakav je bio sustav MYCIN, koji je mogao dijagnosticirati bakterijske krvne infekcije i preporučiti liječenje. Taj je sustav u

Deep Blue,
IBM računalo, težina 1,4 tone

200000000 šahovskih pozicija u sekundi

Posjeduje malo znanja o šahu, ali ogromnu sposobnost izračunavanja

Stroj nema osjećaje niti intuiciju, ne zaboravlja, ne može se zbuniti niti osjećati neugodno

Deep Blue ne uči, a ne može iskoristiti umjetnu inteligenciju da bi naučio od svog protivnika

Izmjene u načinu igre mogu napraviti samo članovi razvojnog tima, i to tek nakon igre

Deep Blue je vrlo vješt u procjeni šahovskih pozicija, no nije u stanju procijeniti slabosti

svoga protivnika

Deep Blue mora provesti temeljito pretraživanje

svih mogućih pozicija da bi odredio optimalni potez nekim slučajevima djelovao čak i bolje od liječnika, no zbog nedostatnih mogućnosti računala tog doba, znanje mu je bilo preusko. Rješenje je nađeno u umrežavanju više tisuća računalnih procesora, što je ostvareno projektom računala Connection Machine. To je računalo bio prvi primjer umjetne neuronske mreže. Iako se područje umjetne inteligencije i dalje razvija, te stalno pronalazi nove primjene, jaka umjetna inteligencija još nije dosegnuta. / Citat dovršen.

$\mathrm{Na}$ ovom mjestu prelazim na polje čiste spekulacije! Zašto? Zato jer bi želio pojasniti neke odrednice koje čine razliku između stroja i čovjeka i njihovih mogućnosti. Godine 1997. obavljeno je zanimljivo takmičenje u šahu: na jednoj strani svjetski šahovski prvak Garry Kasparov, a na drugoj IBM-ovo računalo Deep Blue! Naime, postavilo se zanimljivo pitanje je li računalo Deep Blue inteligentno? Napravit ćemo uspoređivanje, a rezultate prikazati preglednom tablicom:

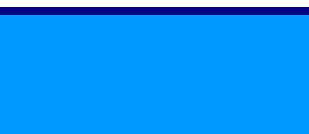

Garry Kasparov, svjetski proak u šahu

3 šahovske poozicije u sekundi

Posjeduje mnogo znanja o šahu, ali bitno manju

sposobnost izračunavanja

Ima osjećaje i istančanu intuiciju, ali može osjećati umor i dosadu te izgubiti koncentraciju

Garry Kasparov je općenito vrlo inteligentan. Autor je nekoliko knjiga i govori mnoge jezike

Garry Kasparov u svakom trenutku može promijeniti svoj način igre

Garry Kasparov je vješt u procjeni svoga protivnika, i u iskorištavanju protivnikovih slabosti

Garry Kasparov je sposoban selektivno

pretraživati da bi odredio sljedeći potez
Možemo ovdje navesti primjer s računalom IBM Watson (projekt DeepQA u kojem je spomenuto računalo 16.2.2011. pobijedilo u igri Jeopardi najbolje ljudske učesnike i osvojilo nagradu od 35.734\$. Naravno, u ovom slučaju nije bio bitan novčani iznos nego tko je uspio odnijeti pobjedu. Čovjek ili stroj? 
Ipak, jedan je od najtežih zadataka umjetne inteligencije strojno prevođenje, odnosno problem obrade prirodnog jezika kao njene podgrane. Kognitivna znanost, per definitionem, znansvena je disciplina koja proučava ljudski um, njegove kognitivne funkcije. U nju se ubrajaju kognitivna psihologija, neuropsihologija, lingvistika, matematika, računalne znanosti, neuroznanost i umjetna inteligencija. Odnosi kognitivne znanosti $\mathrm{i}$ umjetne inteligencije vide se $\mathrm{u}$ tablici:

\section{Kognitivna znanost}

Inteligencija

Umjetna inteligencija

Znanje

Spoznaja

Učenje

Razumijevanje jezika
Obrada informacija

Strojno učenje

Obrada prirodnog jezika
Deskriptivan pojam "inteligencija" sadrži u sebi neke od osobina jedinke ili grupe njih. Mnogo je definicija pojma inteligencija. Tako, primjerice, za inteligenciju R. Pintner navodi da je inteligencija svojstvo uspješnog snalaženje jedinke $\mathrm{u}$ novim situacijama, Burt kaže da je to urođena

opća kognitivna spososobnlost, dok u udžbeniku Psihologija, grupa autora, ŠK, Zagreb, iz 1992. godine, piše da je inteligencija svrsishodno i prilagodljivo ponašanje $u$ danim okolnostima. Dok J. Weizenbaum tumači kako se inteligencija manifestira $u$ odnosu na neki društveni ili kulturni sadržaj. Ili, primjerice, Colvin koji kratko navodi da je to sposobnost učenja prilalgodbe na okolinu.

Ako mi se dozvoli da na ovom mjestu izrazim osobni stav, meni se zaista jako dopada definicija koja je iznesena udžbeniku Psihologija, zagrebačke ŠK iz 1992. godine!

Potrebno je naglasiti da je znamenita Dartmutska konferencija važna zbog otvaranja ili točnije ustanovljavanja jednog novog područja, a to je područje umjetne inteligencije (Dartmouth Conference, Hanover, New Hampshire, 1956.). A ondje i tada John McCarthy izjavljuje: "Umjetna inteligencija je naziv za znanstvenu disciplinu koja se bavi izradnjom računalnih sustava čije se ponašanje može tumačiti kao inteligentno".

Ako pogledate na Internetu odrednicu "Atlas", možete uživati u izvanredno uspješno oblikovanom humanoidnom robotu koji je izradila tvrtka Boston Dynamics, a financirala DARPA, jedna od agencija Ministarstva obrane SAD. Robot je predstavljen javnosti
2013. godine. Naime, radi se o visoko pokretljivom robotu koji je stvoren za rad na otvorenom prostoru i neravnom terenu. Prilagođen je za zadatke potrage i spašavanja, a ogromnu gipkost $\mathrm{i}$ nevjerovatnu stabilnost daju mu 28 hidraulički pokretanih stupnjeva slobode, dva dlana, ruke, noge, stopala i torzo. Na senzorskoj glavi nalazi se stereo kamera i laserski daljinomjer! Znanstvenici su ga prozvali "robo sapiens" (SIC!).

$\mathrm{Na}$ ovom mjestu smatram potpuno oportunim navesti primjer Japana koji je uočivši goleme promjene i izazove kako socijalne, ekonomske i tehnološke, oformio centar za praćenje svih relevantnih zbivanja vezanih za 4 . industrijsku revoluciju. Naime, Japan je odmah kad je primjetio da lagano gubi korak na polju robotike, krenuo u akciju.

Ali interesantno je zabilježiti na kojem su to segmentu japanski stručnjaci uočili da gube korak! Bio je to podatak o broju industrijskih robota na svakih 100 radnika koji učestvuju u proizvodnji!

Evo tablice

Južna Koreja ih koristi 6,31

$\begin{array}{lc}\text { Singapur } & 4,88 \\ \text { Njemačka } & 3,09 \\ \text { Japan } & 3,03 \\ \text { Švedska } & 2,23 \\ \text { Svjetski je prosjek } & 0,74 \\ \text { Kina } & 0,68\end{array}$

Koristeći sve blagodati koje nudi 4 . industrijska revolucija, Japan je ponudio rješenja na polju autonomnih vozila, najnovijih 
rješenja u medicini, umjetnoj inteligenciji i ostalim područjima napredne znanosti. Podatak, odnosno podaci su zapravo kisik za umjetnu inteligenciju, a to bi, smatraju japanski stručnjaci, trebalo upravo Japan postaviti na vodeće mjesto na ovom zanimljivom polju. Izazovi ali i sam napredak je ne samo ogroman nego i veoma, veoma brz! Naime, živimo u vremenu kada se možemo nadati izvanredno dobrim rezultatima na polju neuromorfne znanosti koja ostvaruje vezu između računala i biološkog mozga! Kraj se ne nazire! Umjetna će inteligencija obilježiti naredno razdoblje! Stoga se s razlogom očekuju novi, uspješni rezultati.

\section{Bilješke}

1. Plenković, M., Kučiš, V., Kupinić Guščić, D. Contribution to the development of intercultural communication (Case Study Slovenia). V: Plenković, M. (ur.), et al. (2013.) Društvo i tehnologija - dr. Juraj Plenković = Society and technology - dr. Juraj Plenković : book of abstracts. [Zagreb]: International Federation of Communication Associations - IFCA: Croatian Communication Association - CCA; Maribor: Alma Mater Europaea European Center

2. Plenković, M., Mustić, D. (2013) Croatian media epoch in the new European environment. V: Plenković, M. (ur.), et al. Društvo i tehnologija - $d r$. Juraj Plenković = Society and technology - dr. Juraj Plenković : book of abstracts. [Zagreb]: International Federation of Communication Associations IFCA: Croatian Communication Association CCA; Maribor: Alma Mater Europaea - European Center

3. Plenković, M. (2014) Medijska komunikacija = Media communication. Zagreb: Hrvatsko komunikološko društvo

\title{
ARTIFICIAL INTELLIGENCE
}

\author{
Vladimir Prister \\ Croatian Communication Association \& Hrvatska radio -televizija, Zagreb, Croatia
}

\begin{abstract}
An short historical introduction on all of four industrial revolution are presented. The author displays seven segments of 4 . industrial revolution because of their importance. The article describes some very important aspects of the artificial intelligence (AI) \& their impact. Mentioned examples of complex relationship between machine - man (IBM Deep Blue and IBM Watson). Emphasized the importance of the Dartmouth Confrence in Hanover, New Hampshire, 1956. The great opportunities presented by the example of the Atlas humanloid robot (Boston Dynamics - DARPA). Finally, there is an example of Japan that fights for primacy in this very interesting field.
\end{abstract}

Key words

Artificial intellegence, industrial revolution, future 